\title{
Potential MRI findings associated with inguinal hernia and inguinal canal posterior wall weakness in athletes
}

\author{
Gian Nicola Bisciotti ${ }^{1}$ \\ Alessio Auci ${ }^{2}$ \\ Emanuele Cena ${ }^{1}$ \\ Alessandro Corsin $\mathrm{i}^{3}$ \\ Andrea Bisciotti ${ }^{4}$ \\ Raul Zini ${ }^{5}$ \\ Alessandro Bisciotti ${ }^{4}$ \\ Cristiano Eirale ${ }^{1}$ \\ Federica Parra ${ }^{4}$ \\ Gabriella Gassaghi ${ }^{4}$ \\ Francesco Di Marzo 6 \\ Zarko Vuckovic ${ }^{1}$ \\ Alessandro Quaglia3,7 \\ Piero Volpi $i^{3,7}$
}

1 Qatar Orthopaedic and Sport Medicine Hospital, FIFA Center of Excellence, Doha, Qatar

2 UOS Angiografia e Radiologia interventistica, Ospedale delle Apuane, Massa-Carrara, Italy

${ }^{3}$ FC Internazionale Medical Staff, Milan, Italy

${ }^{4}$ Centro Studi Kinemove Rehabilitation Centers, Pontremoli (MS), Italy

5 Maria Cecilia Hospital-GVM Care and Research, Cotignola (RA), Italy

6 Ospedale Unico della Versilia, Asl Nordovest, Lido di Camaiore, Lucca, Italy

7 Department of Knee Orthopaedic and Sport and Traumatology Unit, Humanitas Research Hospital, Rozzano (MI), Italy

Corresponding author:

Piero Volpi

Department Knee Orthopedic and Sports

Traumatology Unit

Humanitas Research Hospital

Via Manzoni 56

20089 Rozzano (MI), Italy

E-mail: piero.volpi@humanitas.it

\section{Summary}

Introduction: Inguinal hernia and inguinal canal posterior wall weakness, are a frequent clinical issue in chronic groin pain syndrome. The gold standard imaging is represented by dynamic ultrasound (US), with a high positive predictive value in case of inguinal and sport hernia. However, it is important to consider that groin pain syndrome may be caused by several clinical conditions that often are detectable only with magnetic resonance (MRI) assessment.

Methods: In an observational cross sectional study, 120 patients suffering from groin pain syndrome caused by inguinal hernia and/or inguinal canal posterior wall weakness diagnosed by clinical assessment and US examination, underwent a MRI protocol validated for pelvis and pubic area assessment. The same protocol was performed on a control group of $\mathbf{4 0}$ asymptomatic subjects.

Results: Several MRI findings are strongly associated with the presence of inguinal hernia and/or inguinal canal posterior wall weakness.

Conclusions: The presence of some specific MRI findings can make suspect the presence of inguinal hernia or inguinal canal posterior wall weakness.

Level of evidence: Level IV. Observational cross sectional study.

KEY WORDS: groin pain syndrome, inguinal hernia, inguinal canal posterior wall weakness, MRI, US.

\section{Introduction}

Groin pain syndrome (GPS) can be caused by many clinical entities, including inguinal hernia $(\mathrm{IH})^{1-3}$ and inguinal canal posterior wall weakness (ICPWW $)^{3,4}$. The inguinal canal posterior wall weakness is the presence of a bulging without signs of a "true" hernia and without the presence of a real hernia $\operatorname{sac}^{3,4}$. This condition is described in literature using different terms, like "Gilmore's groin"5, "incipient hernia"6, "hockey groin"7, "groin disruption"8, "inguinal disruption"1, "inguinal related groin pain"2, "sportsman's hernia"9, "sportsman's groin"10, "sport hernia"11. However, in according with the guidelines of Groin Pain Syndrome Italian Consensus Conference on Terminology, Clinical Evaluation and Imaging Assessment in Groin Pain in Athlete $^{3}$, we prefer in this study to define this specific condition using the term of ICPWW. Both IH and ICPWW represent an important disability source and are often an important cause of time loss from sport activities in athletes ${ }^{12,13}$. The gold standard in imaging for $\mathrm{IH}$ and ICPWW assessment is currently the dynamic US ${ }^{14}$. Dynamic US shows a positive predictive value (PPV) between $91-100 \%$ for 
IH and ICPWW'14-17. However, GPS may be caused by several clinical conditions ${ }^{2,3,18}$ often each other associated ${ }^{3,4,19,20}$. Many of these clinical frameworks can be observed by $M R I^{11,18,21-31}$. The aim of this cross sectional study was to verify, with a MRI protocol previously validated for GPS assessment ${ }^{30}$, the potential radiological findings associated with $\mathrm{IH}$ and ICPWW.

\section{Material and methods}

\section{Study design}

Observational cross sectional study on 120 patients clinically and radiologically diagnosed of GPS, caused by $\mathrm{IH}$ and/or ICPWW (diagnosed by clinical assessment and US examination). All of them underwent to an MRI protocol ${ }^{30}$ for the assessment of the pelvis and the pubic area. Ethical approval and written consent by each participant were obtained. The STROBE statement ${ }^{32}$ supplemented by TIDieR checklist and guide ${ }^{33}$ were followed for the creation of the study design. Furthermore, when designing this study both the Minimal Reporting Standard for Groin Pain in Athlete ${ }^{34}$ and Groin Pain Syndrome Italian Consensus Conference on Terminology, Clinical Evaluation and Imaging Assessment in Groin Pain in Athlete $^{3}$ were consulted. The Authors declare that this research was conducted ethically according to the principles in line with the Declaration of Helsinki and that this study respects basic principles and recommendations in clinical and field science research required by Muscle, Ligaments and Tendons Journal ${ }^{35}$.

\section{Setting}

The study included a Study Group (SG) and a Control Group (CG). All patients (172 subjects) registered to our Groin Pain Clinical Centre complaining GPS during the period between December 2015 and May 2016 were included in the SG. All patients were examined by an experienced sports medicine physician, an abdominal surgeon and the images were reviewed by two radiologists in a blinded manner. The clinical assessment was performed according with the guidelines from the Groin Pain Syndrome Italian Consensus Conference on terminology, clinical evaluation and imaging assessment in groin pain in athletes (GPSICC) ${ }^{3}$. There were 40 subjects in the CG.

\section{Eligibility criteria}

Inclusion and exclusion criteria were established in accordance with the GPSICC guidelines.

The inclusion criteria for the SG were being a patient with a GPS clinical framework caused by IH or ICP. WW and diagnosed by clinical assessment and dynamic US examination. Exclusion criteria were having an acute GPS framework due to indirect muscle injury. Furthermore, all the patients showing a GPS clinical framework due to other causes were also excluded. Inclusion criteria for the CG provided were being a healthy subject practicing sport activities with no experience of GPS during the last year and with demographic data similar to the SG group.

\section{Participants}

According to the above mentioned eligibility criteria of the SG, 35 subjects who showed indirect muscle injury at adductors, ileopsoas and rectus abdominis muscles level, 1 subject with pubic symphysis stress fracture, 3 subjects showing apophysitis at anterior inferior iliac spine, 6 subjects with apophysitis at anterior superior iliac spine, 1 subject with apophysitis at ischial tuberosity level, and 6 subjects with gynaecological frameworks were excluded from the study. Following these exclusions criteria, 120 patients were enrolled in the study. Subsequently all the subjects underwent an $\mathrm{MRI}$ protocol${ }^{30}$ for the assessment of the pubic area.

\section{Demographic data}

The following demographic data, both for SG and $\mathrm{CG}$, were recorded: gender, age, height, body weight. Furthermore, the duration of GPS symptoms in SG subjects was recorded and its average subsequently calculated.

The age, height and body weight of the 116 men and 4 women enrolled in the SG were respectively 29.58 \pm 9.85 years, $177.51 \pm 5.72 \mathrm{~cm}$ and $75.25 \pm 9.21 \mathrm{~kg}$. The age, height and body weight of 10 men and 10 women enrolled in the CG were respectively $29.53 \pm$ 8.73 years, $178.32 \pm 4.92 \mathrm{~cm}$ and $77.19 \pm 8.11 \mathrm{~kg}$. The average duration of GPS symptoms in the subjects of $S G$ was $13.93 \pm 3.6$ months.

The type and level of sport activity and the years of practice, both for SG and CG, are shown in Table and Table II respectively.

\section{US protocol}

The US examination was performed by 2 different expert radiologists in a blinded manner using the same equipment (TERASON U SMART 3300 linear probe $15-4 \mathrm{MHz}$ ). The protocol was in conformity with the GPSICC guidelines ${ }^{3}$ and in particular the definition of $\mathrm{IH}$ and ICPWW followed met the following criteria:

- IH is classified as a hernia sac, which occupy more or less deeply the inguinal canal, clearly visible through an US image

- ICPWW is classified as a bulging with no the presence of hernia sac, through an US image observation.

The $\mathrm{IH}$ were classified according to European Hernia Society classification ${ }^{36}$, as direct hernia (M1, M2, $M 3)$, indirect hernia (L1, L2, L3) and femoral hernia (F1, F2, F3).

\section{MRI protocol}

The MRI protocol was in conformity with the protocol suggested by Branci et al. ${ }^{30}$ and provided the use of a 1.5 Tesla MRI (SIEMENS MAGNETOM Espree 1.5 $\mathrm{T}$ open bore). During the examination, patients were in supine position and the surface coil was centred at the pubic symphysis covering the total pelvic area. 
Table I. Type of sports activity, level and years of practice of the subjects enrolled in the SG.

\begin{tabular}{llll}
\hline Sports activity (\% of total) & $\begin{array}{l}\text { Professionals (\% of total } \\
\text { athletes practicing the } \\
\text { same sport) }\end{array}$ & $\begin{array}{l}\text { Amateurs (\% of total } \\
\text { athletes practicing the } \\
\text { same sport) }\end{array}$ & $\begin{array}{l}\text { Average years of practice } \\
\pm \text { standard deviation) }\end{array}$ \\
\hline Soccer $81(67.50 \%)$ & $10(12.35 \%)$ & $71(87.65 \%)$ & $18.81 \pm 3.75$ \\
Basketball 3 (2.50\%) & --- & $3(100 \%)$ & $10.31 \pm 2.11$ \\
Volleyball 3 (2.50\%) & & $3(100 \%)$ & $11.21 \pm 3.83$ \\
Ski 1 $(0.83 \%)$ & & 11 \\
Tennis $4(3.33 \%)$ & $3(100 \%)$ & $8.56 \pm 6.41$ \\
Other recreational activities & --- & $28(100 \%)$ & $11.81 \pm 5.30$ \\
$28(23.33 \%)$ & & & \\
\hline
\end{tabular}

Table II. Type of sports activity, the level and years of practice of the subjects enrolled in the CG.

\begin{tabular}{llll}
\hline Sports activity & Professionals & Amateurs & $\begin{array}{l}\text { Years of practice (average } \pm \text { standard } \\
\text { deviation) }\end{array}$ \\
\hline Soccer $26(65.00 \%)$ & --- & $26(100 \%)$ & $17.81 \pm 4.73$ \\
Basketball 1 $(2.50 \%)$ & --- & $1(100 \%)$ & 12 \\
Volleyball 1(2.50\%) & --- & $1(100)$ & 14 \\
Tennis 2 (5\%) & --- & $2(100 \%)$ & $8.522 \pm 5.39$ \\
Other recreational activities & --- & $10(100 \%)$ & $12.31 \pm 4.93$ \\
$10(25.00 \%)$ & & & \\
\hline
\end{tabular}

The MRI sequence provided the acquisition of images weighed in T1, T2 Fat Sat, STIR and PD Fat Sat into the coronal, axial, sagittal and axial oblique plans. The axial oblique plane was oriented $50^{\circ}$ from the horizontal one, and it was placed parallel to the long axis of the superior pubic rami. The total duration of the protocol was about 40 '.

The MRI protocol was evaluated by 2 different expert radiologists in blinded manner. In the MRI evaluation protocol the presence of the following findings was verified:

I. bone marrow oedema (BMO)

II. fatty infiltration in bone marrow at symphyseal joint level (FI)

III. symphyseal sclerosis (SS)

IV. parasymphyseal high-intensity line (PHIL)

V. secondary inferior cleft sign (SICS)

VI. secondary superior cleft sign (SSCS)

VII.subchondral cysts / joint surface irregularities (SC-JI)

VIII.central disc protrusion (CDP)

IX. adductor longus tendinopathy (ALT)

$X$. rectus abdominis tendinopathy (RAT).

The MRI sequences and the details of acquisition are specified in the Table III.

\section{Statistical analysis}

The $\mathrm{k}$ values for inter-observer reliability for US and MRI findings were calculated.

The data recorded during the MRI protocol in SG and
CG were compared with Fisher's exact test to compare the proportion of two groups for each considered value. A logistic regression was performed on the significant possible value inferred by the Fisher's exact test. The statistical significance was set to $p<0.05$.

\section{Results}

The results of US findings for the SG are showed in Table IV.

The inter-observer reliability values concerning US findings in the SG are showed in Table V.

The findings of MRI studies in the SG are showed in Table VI.

The inter-observer reliability values concerning MRI findings in the SG are showed in Table VII.

The association of US and MRI findings in the SG is showed in Table VIII.

No subject belonging to the CG was positive for inguinal pathology at the US examination. The results of MRI findings in the CG are showed in Table IX.

The inter-observer reliability values concerning MRI findings in the $C G$ are showed in Table $X$.

The correlation matrix between the MRI findings in SG is showed in Table XI.

The correlation matrix between MRI findings in CG is showed in Table XII. 
Table III. The MRI sequences and the details of acquisition concerning the protocol used in the study (from Branci et al. ${ }^{30}$ ).

\begin{tabular}{ll}
\hline MRI finding & MRI sequences \\
\hline Bone marrow oedema grade 0-3 & $\begin{array}{l}\text { Coronal STIR and T1. Axial } \\
\text { oblique* T2 FS and PD Fat } \\
\text { Sat. }\end{array}$
\end{tabular}

Description

The presence of a diffused area of increased intensity in fluid-sensitive sequences and the presence of a decreased signal on $\mathrm{T} 1$ sequences, at pubic symphysis level. The BMO staging is performed in accordance with the following parameters:

The extension of $\mathrm{BMO}$ is measured on the oblique axial sequences PD FS or T2 FS along the long axis of the upper or lower pubic branch.

The degree of $\mathrm{BMO}$ is based on the area of the signal intensity of the largest extension. A line parallel to the long axis of the upper or lower branch of the middle pubic should be drawn. This line should be median to the anterior and posterior margins of the pubic branch. The extension of $\mathrm{BMO}$ is based on the distance existing from the insertion point of this line and the joint surface of the symphysis. The measurement is performed just to the point where, on this line, the increased intensity signal is visible.

The degree of $\mathrm{BMO}$ is determined according to this distance as follows:

grade 0 : no $\mathrm{BMO}$, grade 1 : $\mathrm{BMO} \leq 1 \mathrm{~cm}$, grade 2 : $\mathrm{BMO}$ $\geq 1 \mathrm{~cm}$ and $\leq 2 \mathrm{~cm}$, grade $3: B M O \geq 2 \mathrm{~cm}$.

Fatty infiltration in bone marrow at symphyseal joint level

Symphyseal sclerosis

Parasymphyseal high-intensity line

Secondary inferior cleft sign

Secondary superior cleft sign

Subchondral cyst / joint surface irregularities

Central disc protrusion

Adductor longus tendinopathy

Rectus abdominis tendinopathy
Coronal T1 and STIR. Axial

Presence of high intensity signal areas at symphysis oblique T2 Fat Sat and PD Fat Sat.

Coronal T1. Axial oblique T1.

Axial oblique PD Fat Sat. Coronal STIR.

Coronal STIR.

Axial oblique PD Fat Sat. Coronal PD Fat Sat. Sagittal STIR.

Coronal STIR. Axial oblique Fat Sat.

Coronal STIR

Axial oblique PD Fat Sat

Coronal T1.

Axial oblique T1.

Axial oblique PD Fat Sat, T2 Fat Sat and T1.

Coronal T1.

Sagittal STIR

Axial oblique PD Fat Sat. level in T1 weighed sequences and presence of low intensity signal areas in Fat Sat sequences.

Presence of bone sclerosis along the joint margins of the symphysis.

Presence of a high-intensity signal line in fluid-sensitive sequences dislocated within the pubic bone.

The high intensity line is not in communication with the symphysis joint space.

Presence of a high-intensity signal line extending laterally and inferiorly to the lower part of the symphysis. This line is in communication with the symphysis joint space.

Presence of a high-intensity signal line in fluid-sensitive sequences extending parallel to the lower margin of the upper pubic branch. This line, as the secondary inferior cleft sign, is in communication with the symphysis joint space.

Presence of subchondral cyst (round hyper-intense element on T2 weights images) and / or irregularities of the joint surface.

Protrusion of the central fibrous symphysis disk.

Increasing of the signal intensity in the fluid-sensitive sequences within the tendon of the adductor longus and / or its enthesis (intra substantia) and / or swelling of the tendon or enthesis morphology.

Increasing of the signal intensity in the fluid-sensitive sequence at muscle-tendon junction level and /or increasing of the volume of the tendon.

*The oblique axial plane should be oriented approximately $50^{\circ}$ with respect to the horizontal plane and parallel to the long axis of the upper pubic branch."

Legend: BMO, bone marrow oedema; PD Fat Sat; proton density fat saturation; STIR, short tau inversion recovery. 
Table IV. Results of US findings in the SG. It is important to note that most of the subject $(45.8 \%)$ presented a bilateral ICPWW.

\begin{tabular}{lll}
\hline US findings & Number & Percentage \\
\hline ICPWW (right) & 19 & 15,8 \\
ICPWW (left) & 18 & 15 \\
ICPWW (bilateral) & 55 & 45,8 \\
M1 (right) & 1 & 0,8 \\
M1 (left) & 1 & 0,8 \\
M1 (bilateral) & 6 & 5 \\
L1 (left) & 1 & 0,8 \\
L1 (bilateral) & 1 & 0,8 \\
F1(right) & 1 & 0,8 \\
ICPWW (right) + M1 (left) & 6 & 5 \\
ICPWW (left) + M1 (right) & 7 & 5,8 \\
ICPWW (right) + L1 (left) & 4 & 3,3 \\
Summary & $\mathbf{1 2 0}$ & $\mathbf{1 0 0}$
\end{tabular}

Table V. The inter-observer reliability values concerning US findings in the SG.

\begin{tabular}{lll}
\hline US findings & $\begin{array}{l}\text { Inter-observer } \\
\text { reliability } \\
\text { (k value) }\end{array}$ & $\begin{array}{l}\text { Confidence } \\
\text { interval }(\mathbf{C l}) \\
\mathbf{( 9 5 \% )}\end{array}$ \\
\hline F1 & 1 & 1 \\
M1 & 0.76 & $0.70-0.82$ \\
M2 & 0.74 & $0.66-0.82$ \\
L1 & 0.75 & $0.70-0.80$ \\
L2 & 0.76 & $0.69-0.83$ \\
ICPWW & 0.77 & $0.72-0.81$ \\
\hline
\end{tabular}

The results of the Fisher's exact test are showed in Table XIII.

The logistic regression revealed only 3 significant $\mathrm{MRI}$ findings correlated with the presence of $\mathrm{IH}$ and ICPWW. The results are showed in Table XIV.

The BMO average grade in case of ICPWW was $1.28 \pm 0.45$.

The BMO average grade in case of $\mathrm{IH}(\mathrm{F} 1, \mathrm{M} 1-\mathrm{M} 2$, L1-L2) was 2.77 \pm 0.44 .

The difference was statistically significant $(p<0.05)$.

\section{Discussion}

The main finding of this study is the correlation of some specific MRI findings, derived from a standard $\mathrm{MRI}$ protocol, with the presence of inguinal pathologies (i.e. IH and ICPWW). To our knowledge this is the first study present in the literature showing this correlation and these results could be clinically rele-
Table VI. Findings of MRI studies in the SG. The most widespread clinical frameworks are CDP (55.83\%), ALT $(47.17 \%)$ and BMO (28.33\%).

\begin{tabular}{lll}
\hline MRI findings & Number & Percentage (\%) \\
\hline BMO & 34 & 28.33 \\
BMO grade I & 18 & 52.29 (of the total BMO) \\
BMO grade II & 9 & 26.47 (of the total BMO) \\
BMO grade III & 7 & 20.58 (of the total BMO) \\
FI & 6 & 5 \\
SS & 60 & 50 \\
PHIL & 6 & 5 \\
SSCS & 4 & 3.33 \\
SICS & 13 & 10.83 \\
SC-JI & 23 & 19.17 \\
CDP & 67 & 55.83 \\
ALT & 59 & 47.17 \\
RAT & 8 & 6.67 \\
\hline
\end{tabular}

Table VII. The inter-observer reliability values concerning MRI findings in SG.

\begin{tabular}{lll}
\hline MRI findings & $\begin{array}{l}\text { Inter-observer } \\
\text { reliability } \\
\text { (k value) }\end{array}$ & $\begin{array}{l}\text { Confidence } \\
\text { interval }(\mathbf{C I}) \\
\mathbf{( 9 5 \% )}\end{array}$ \\
\hline BMO & 0.77 & $0.70-0.84$ \\
FI & 0.60 & $0.52-0.68$ \\
SS & 0.74 & $0.67-0.81$ \\
PHIL & 0.61 & $0.53-0.69$ \\
SSCS & 0.76 & $0.69-0.83$ \\
SICS & 0.78 & $0.71-0.85$ \\
SC-JI & 0.75 & $0.68-0.82$ \\
CDP & 0.82 & $0.79-0.89$ \\
ALT & 0.61 & $0.53-0.69$ \\
RAT & 0.62 & $0.54-0.71$
\end{tabular}

vant for an accurate GPS diagnosis ${ }^{3,21}$.

In the present study, some MRI findings (ALT, CDP and $\mathrm{BMO}$ ) are frequently associated with the presence of $\mathrm{IH}$ and ICPWW with an OR value respectively equal to $3.83,3.77$ and 3.68 , respectively. They are an indirect evidence of mechanical overload stress both at symphysis (BMO and CDP) and tendon level (ALT and BMO) but also of symphysis intrinsic instability (CDP) 3,4,30,31. Many studies show that mechanical stress at symphysis level can cause inguinal pathologies ${ }^{4,37-39}$, therefore the results of this study suggest that some MRI findings correlated with symphysis mechanical stress 
Table VIII. The association of US and MRI findings in the SG.

\begin{tabular}{lllllllllll}
\hline & BMO & FI & SS & PHIL & SSCS & SICS & SC-JI & CDP & ALT & RAT \\
\hline ICPWW & 25 & 4 & 42 & 4 & 3 & 10 & 16 & 54 & 45 & 7 \\
M1 & 2 & 2 & 5 & 2 & 1 & 2 & 2 & 6 & 5 & -- \\
L1 & 0 & -- & -- & -- & -- & -- & 1 & & 1 & -- \\
F1 & 0 & -- & 1 & & & & & & 1 \\
ICPWW (right) + M1 (left) & 2 & -- & 2 & -- & -- & 1 & 2 & 2 & -- & 1 \\
ICPWW (left) + M1 (right) & 2 & -- & 5 & -- & -- & -- & 1 & 4 & 3 & - \\
\hline
\end{tabular}

Table IX. Results of MRI findings in the CG.

\begin{tabular}{lll}
\hline MRI findings & Number & Percentage (\%) \\
\hline BMO & 2 & 5 \\
BMO grade I & 2 & 100 (of the total BMO) \\
BMO grade II & -- & -- \\
BMO grade III & -- & -- \\
FI & -- & -- \\
SS & 5 & 12.5 \\
PHIL & -- & -- \\
SSCS & -- & -- \\
SICS & -- & -- \\
SC-JI & 4 & 10 \\
CDP & 5 & 12.5 \\
ALT & 5 & 12.5 \\
RAT & -- & -- \\
\hline
\end{tabular}

overload and its intrinsic instability may indicate the presence of an IH and/or ICPWW.

This study shows a high inter-observer reliability for the different US (range $1-0.74$ ) and RM (range 0.82 -0.61) findings, these values are in line with the data present in literature ${ }^{22,23}$.

\section{MRI findings}

\section{ALT (Adductor longus tendinopathy)}

ALT finding at the MRI is the most important radiological sign (OR $3.83 ; 1.27$ to $11.54 ; 95 \% \mathrm{Cl}$ ) correlated with $\mathrm{IH}$ and ICPWW. Obviously, this does not exclude the possibility of ALT MRI finding without the presence of inguinal pathology.

The ALT (Fig. 1) is radiologically represented by an increasing of the signal intensity at adductor longus $(A L)$ tendon and/or at its enthesis level in the fluidsensitive sequences. Tendon swelling and/or changes in enthesis morphology is usually also pre-
Table X. The inter-observer reliability values concern ing MRI findings in CG.

\begin{tabular}{lll}
\hline MRI findings & $\begin{array}{l}\text { Inter-observer } \\
\text { reliability } \\
\text { (k value) }\end{array}$ & $\begin{array}{l}\text { Confidence } \\
\text { interval }(\mathbf{C I}) \\
\mathbf{( 9 5 \% )}\end{array}$ \\
\hline BMO & 0.80 & $0.78-0.83$ \\
SS & 0.74 & $0.66-0.82$ \\
SC-JI & 0.76 & $0.70-0.81$ \\
CDP & 0.82 & $0.78-0.90$ \\
ALT & 0.63 & $0.54-0.70$ \\
\hline
\end{tabular}

sent. On the contrary, in physiological situations, the tendon appears in all the sequences hypo-intense, subtle and well-defined while in axial oblique sequences the tendon appears symmetric, of triangular shape with the base facing the anterior margin of the pubic bone. In the ALT framework, the tendon shows a convex shape and increased signal intensity. In our study, ALT is present in $59 \%$ of the SG subjects versus $12.5 \%$ of the CG subjects. This may be explained by the long duration of GPS symptoms in SG subjects that was $13.93 \pm 3.6$ months in average. Such long symptoms duration allows us to classify the GPS framework as "long standing GPS" (LSGPS or chronic GPS) in according with Groin Pain Syndrome Italian Consensus Conference on terminology, clinical evaluation and imaging assessment in groin pain in athlete $^{3}$. In a LSGPS, the clinical framework is frequently based on the association of an inguinal pathology and a pubic osteitis $(P O)^{3,4,19}$. It is important to remember that a PO framework is strongly associated with a chronic $\mathrm{ALT}^{29,40}$. Furthermore, a radiological framework of PO includes SS, SC-JI and $\mathrm{BMO}^{29,41}$. Indeed, in the subjects of $S G$ suffering of ALT, MRI findings of SS, SC-JI, BMO and CDP are associated respectively in $33.33,9.17,13.33$ and $35 \%$ of the cases, while in the CG subjects this association was respectively equal to $7.5,7.5,2.5$ and $10.0 \%$ of the cases (all $\mathrm{p}<0.005$ ). Unfortunately, no radiological grading scale is currently able to evaluate 
Table XI. Correlation matrix between the MRI findings in SG.

\begin{tabular}{|c|c|c|c|c|c|c|c|c|c|c|}
\hline & BMO & FI & SS & PHIL & SSCS & SICS & SC-JI & CDP & ALT & RAT \\
\hline BMO & --- & $\begin{array}{l}1 \\
(0.83 \%)\end{array}$ & $24(20)$ & $\begin{array}{l}3 \\
(2.5)\end{array}$ & $\begin{array}{l}2 \\
(1.67)\end{array}$ & $7(5.83)$ & $\begin{array}{l}13 \\
(10.83) \\
\end{array}$ & $\begin{array}{l}28 \\
(23.33) \\
\end{array}$ & $\begin{array}{l}16 \\
(13.33)\end{array}$ & $\begin{array}{l}4 \\
(3.33)\end{array}$ \\
\hline FI & $\begin{array}{l}1 \\
(0.83)\end{array}$ & -- & $\begin{array}{l}5 \\
(4.17)\end{array}$ & $\begin{array}{l}1 \\
(0.83)\end{array}$ & $\begin{array}{l}1 \\
(0.83)\end{array}$ & $\begin{array}{l}1 \\
(0.83)\end{array}$ & $\begin{array}{l}3 \\
(2.50)\end{array}$ & $\begin{array}{l}4 \\
(3.33)\end{array}$ & $\begin{array}{l}4 \\
(3.33)\end{array}$ & $\begin{array}{l}2 \\
(1.67)\end{array}$ \\
\hline SS & $\begin{array}{l}24 \\
(20)\end{array}$ & $\begin{array}{l}5 \\
(4.17)\end{array}$ & --- & $\begin{array}{l}2 \\
(1.67)\end{array}$ & $\begin{array}{l}3 \\
(2.5)\end{array}$ & $\begin{array}{l}12 \\
(10)\end{array}$ & $\begin{array}{l}17 \\
(14.17)\end{array}$ & $\begin{array}{l}46 \\
(38.33)\end{array}$ & $\begin{array}{l}40 \\
(33.33)\end{array}$ & $\begin{array}{l}5 \\
(4.17)\end{array}$ \\
\hline PHIL & $\begin{array}{l}3 \\
(2.5) \\
\end{array}$ & $\begin{array}{l}1 \\
(0.83)\end{array}$ & $\begin{array}{l}2 \\
(1.67)\end{array}$ & -- & $\begin{array}{l}1 \\
(0.83)\end{array}$ & $\begin{array}{l}2 \\
(1.67)\end{array}$ & $\begin{array}{l}3 \\
(2.50) \\
\end{array}$ & $\begin{array}{l}5 \\
(4.17) \\
\end{array}$ & $\begin{array}{l}4 \\
(3.33) \\
\end{array}$ & $\begin{array}{l}1 \\
(0.83)\end{array}$ \\
\hline SSCS & $\begin{array}{l}2 \\
(1.67)\end{array}$ & $\begin{array}{l}1 \\
(0.83)\end{array}$ & $\begin{array}{l}3 \\
(2.5) \\
\end{array}$ & $\begin{array}{l}1 \\
(0.83)\end{array}$ & -- & $\begin{array}{l}1 \\
(0.83)\end{array}$ & $\begin{array}{l}1 \\
(0.83)\end{array}$ & $\begin{array}{l}2 \\
(1.67)\end{array}$ & $\begin{array}{l}4 \\
(3.33) \\
\end{array}$ & $\begin{array}{l}1 \\
(0.83)\end{array}$ \\
\hline SICS & $\begin{array}{l}7 \\
(5.83)\end{array}$ & $\begin{array}{l}1 \\
(0.83)\end{array}$ & $\begin{array}{l}12 \\
(10)\end{array}$ & $\begin{array}{l}2 \\
(1.67)\end{array}$ & $\begin{array}{l}1 \\
(0.83)\end{array}$ & -- & $\begin{array}{l}7 \\
(5.83)\end{array}$ & $\begin{array}{l}13 \\
(10.83)\end{array}$ & $\begin{array}{l}5 \\
(4.17)\end{array}$ & $\begin{array}{l}2 \\
(1.67)\end{array}$ \\
\hline SC-JI & $\begin{array}{l}13 \\
(10.83)\end{array}$ & $\begin{array}{l}3 \\
(2.50) \\
\end{array}$ & $\begin{array}{l}17 \\
(14.17)\end{array}$ & $\begin{array}{l}3 \\
(2.50) \\
\end{array}$ & $\begin{array}{l}1 \\
(0.83)\end{array}$ & $\begin{array}{l}7 \\
(5.83) \\
\end{array}$ & -- & $\begin{array}{l}17 \\
(14.17)\end{array}$ & $\begin{array}{l}11 \\
(9.17)\end{array}$ & $\begin{array}{l}4 \\
(3.33)\end{array}$ \\
\hline CDP & $\begin{array}{l}28 \\
(23.33)\end{array}$ & $\begin{array}{l}4 \\
(3.33)\end{array}$ & $\begin{array}{l}46 \\
(38.33)\end{array}$ & $\begin{array}{l}5 \\
(4.17) \\
\end{array}$ & $\begin{array}{l}2 \\
(1.67)\end{array}$ & $\begin{array}{l}13 \\
(10.83)\end{array}$ & $\begin{array}{l}17 \\
(14.17)\end{array}$ & -- & $\begin{array}{l}42 \\
(35)\end{array}$ & $\begin{array}{l}8 \\
(6.67)\end{array}$ \\
\hline ALT & $\begin{array}{l}16 \\
(13.33)\end{array}$ & $\begin{array}{l}4 \\
(3.33)\end{array}$ & $\begin{array}{l}40 \\
(33.33)\end{array}$ & $\begin{array}{l}4 \\
(3.33)\end{array}$ & $\begin{array}{l}4 \\
(3.33)\end{array}$ & $\begin{array}{l}5 \\
(4.17) \\
\end{array}$ & $\begin{array}{l}11 \\
(9.17\end{array}$ & $\begin{array}{l}42 \\
(35)\end{array}$ & -- & $\begin{array}{l}6 \\
(5) \\
\end{array}$ \\
\hline RAT & $\begin{array}{l}4 \\
(3.33)\end{array}$ & $\begin{array}{l}2 \\
(1.67)\end{array}$ & $\begin{array}{l}5 \\
(4.17)\end{array}$ & $\begin{array}{l}1 \\
(0.83)\end{array}$ & $\begin{array}{l}1 \\
(0.83)\end{array}$ & $\begin{array}{l}2 \\
(1.67)\end{array}$ & $\begin{array}{l}4 \\
(3.33)\end{array}$ & $\begin{array}{l}8 \\
(6.67)\end{array}$ & $\begin{array}{l}6 \\
(5)\end{array}$ & -- \\
\hline
\end{tabular}

Table XII. Correlation matrix between MRI findings in CG.

\begin{tabular}{|l|l|l|l|l|l|l|l|l|l|l}
\hline & BMO & FI & SS & PHIL & SSCS & SICS & SC-JI & CDP & ALT & RAT \\
\hline BMO & --- & 0 & $\begin{array}{l}1 \\
(2.5)\end{array}$ & 0 & 0 & 0 & $\begin{array}{l}1 \\
(2.5)\end{array}$ & $\begin{array}{l}1 \\
(2.5)\end{array}$ & $\begin{array}{l}1 \\
(2.5)\end{array}$ & 0 \\
\hline FI & 0 & --- & 0 & 0 & 0 & 0 & 0 & 0 & 0 & 0 \\
\hline SS & $\begin{array}{l}1 \\
(2.5)\end{array}$ & 0 & --- & 0 & 0 & 0 & $\begin{array}{l}4 \\
(10)\end{array}$ & $\begin{array}{l}4 \\
(10)\end{array}$ & $\begin{array}{l}3 \\
(7.5)\end{array}$ & 0 \\
\hline PHIL & 0 & 0 & 0 & --- & 0 & 0 & 0 & 0 & 0 & 0 \\
\hline SSCS & 0 & 0 & 0 & 0 & --- & 0 & 0 & 0 & 0 & 0 \\
\hline SICS & 0 & 0 & 0 & 0 & 0 & --- & 0 & 0 & 0 & 0 \\
\hline SC-JI & $\begin{array}{l}1 \\
(2.5)\end{array}$ & 0 & $\begin{array}{l}4 \\
(10)\end{array}$ & 0 & 0 & 0 & --- & $\begin{array}{l}4 \\
(10)\end{array}$ & $\begin{array}{l}3 \\
(7.5)\end{array}$ & 0 \\
\hline CDP & $\begin{array}{l}1 \\
(2.5)\end{array}$ & 0 & $\begin{array}{l}4 \\
(10)\end{array}$ & 0 & 0 & 0 & $\begin{array}{l}4 \\
(10)\end{array}$ & $\begin{array}{l}--- \\
(10)\end{array}$ & 0 \\
\hline ALT & $\begin{array}{l}1 \\
(2.5)\end{array}$ & 0 & $\begin{array}{l}3 \\
(7.5)\end{array}$ & 0 & 0 & 0 & $\begin{array}{l}3 \\
(7.5)\end{array}$ & $\begin{array}{l}4 \\
(10)\end{array}$ & $\begin{array}{l}-- \\
0\end{array}$ \\
\hline RAT & 0 & 0 & 0 & 0 & 0 & 0 & 0 & 0 & 0 & -- \\
\hline
\end{tabular}

the severity of tendinopathy at ALT level28. However, it is necessary to note that in some cases ALT, as well as SS, may reflect a functional adaptation against a functional overload due to a hard sport activity $24,30,31,42$.

\section{CDP (Central disc protrusion)}

In our series, CDP diagnosed at MRI study is present in $67 \%$ of the subjects belonging to SG versus $12.5 \%$ in subjects of CG and represents the second most important radiological sign associated with $\mathrm{IH}$ and ICPWW (OR 3.77; 1.19 to11.92; 95\% Cl).

The CDP (Fig. 2) is observable in coronal and axial oblique T1 weighted images. In the coronal images the central disk cranially protrudes in respect to the symphysis joint edges, while in the axial images it protrudes posteriorly. The symphysis joint shows many anatomic-functional similarities with the inter- 
Table XIII. Results of the Fisher's exact test.

\begin{tabular}{ll}
\hline MRI findings & P value \\
\hline BME & $<0.001$ \\
FI & 0,338 \\
SS & $<0.001$ \\
PHIL & 0,338 \\
SICS & 0,039 \\
SSCS & 0,999 \\
SC-JI & 0,573 \\
CDP & $<0.001$ \\
ALT & $<0.001$ \\
RAT & 0,202 \\
\hline
\end{tabular}

Table XIV. Result of logistic regression. OR: odds ratio.

\begin{tabular}{lll}
\hline MRI findings & OR $(95 \% \mathbf{C l})$ & p value \\
\hline ALT & $3.83(1.27$ to 11.54$)$ & 0.017 \\
CDP & $3.77(1.19$ to 11.92$)$ & 0.024 \\
BMO & $3.68(0.74$ to 18.23$)$ & 0.111 \\
\hline
\end{tabular}

vertebral joint $30,31,41$. Indeed, both types of joints are amphiarthrosis with a central disk and an adjacent bone marrow containing hematopoietic tissue ${ }^{41}$. Therefore, it is possible to correlate, at least in some aspects, the degenerative changes at the symphysis level observable in a GPS framework to those found in the spinal degeneration, described by Modic et al. ${ }^{43}$ as follows:

I. degeneration of the intervertebral disc (Modic type I)

II. fat infiltration (Modic type II)

III. fibrosis and sclerosis (Modic type III and IV).

Therefore the presence of CDP is comparable to a Modic type I and can be considered a typical sign of functional overload at symphysis level $3,30,31$. Furthermore, the CDP is an important indirect sign of symphysis instability caused by functional overload ${ }^{3}$. This instability may cause an important mechanical stress at posterior inguinal wall level leading therefore to the onset of inguinal pathologies ${ }^{4}$.

\section{BMO (Bone marrow oedema)}

In our study BMO is present in $28.33 \%$ of the subjects belonging to SG versus $5 \%$ of the subject in the CG. In the subjects in SG, BMO is associated with ALT, SS, SC-JI, and CDP respectively for 13.33, 20, $10.83 \%$ and $23.3 \%$, while in the CG this association was respectively equal to $2.5 \%$ for all considered MRI findings (all $p<0.005$ ).

A BMO (Fig. 3) is the presence of an area of increased intensity in fluid-sensitive sequences and, in the same time, the presence of a decreased signal on T1 sequences, at pubic symphysis level. The BMO staging is performed, in accordance with is extension, in grade $0-1^{30,31}$. BMO is present on average in $90 \%$ of the athletes suffering from GPS $21,44,45$. However, it is not yet fully understood whether BMO is only a marker of "bone stress injury" or it represents a primary source of pain in the patient affected by GPS 46 .

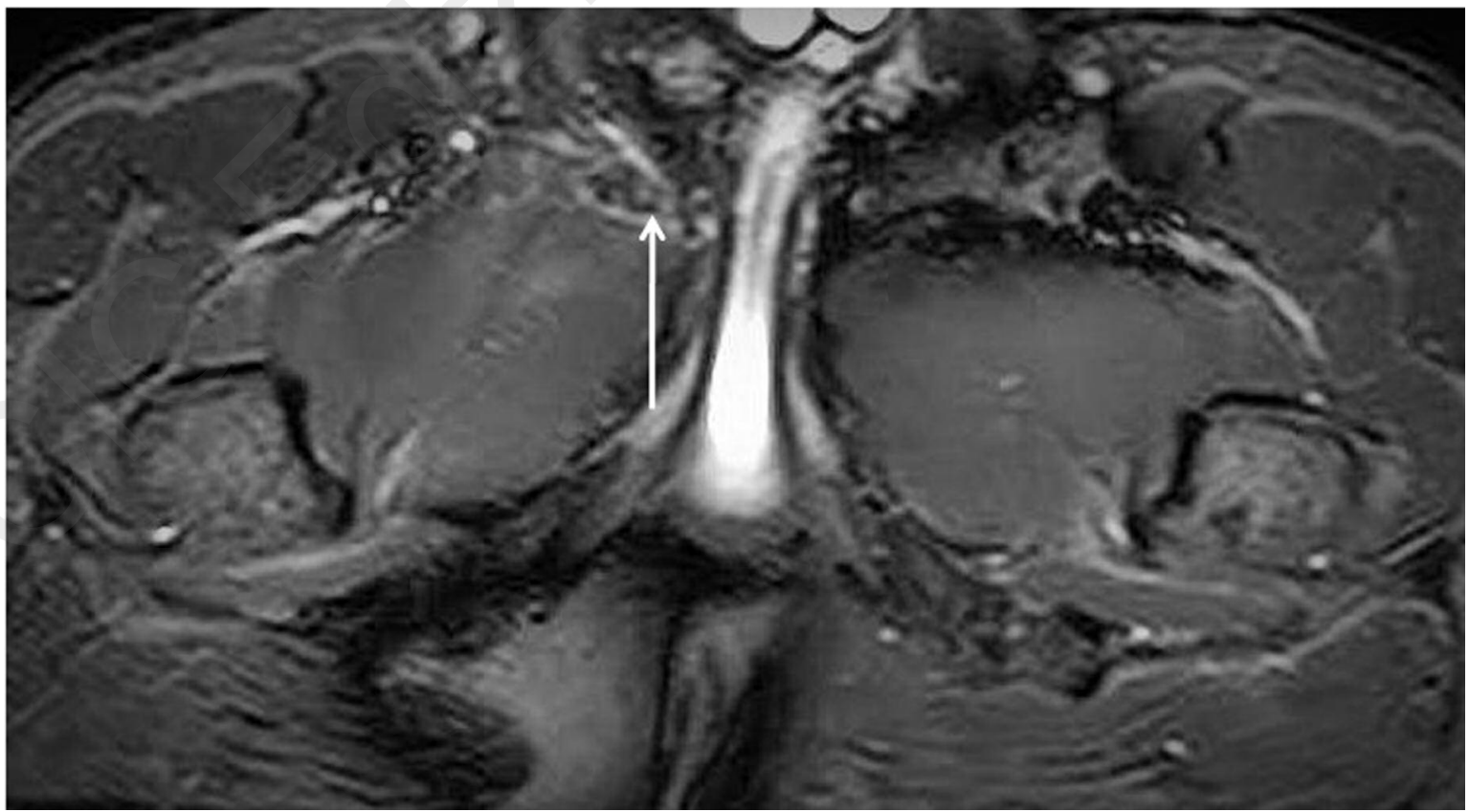

Figure 1. Axial oblique PD Fat Sat showing adductor longus tendinopathy. 


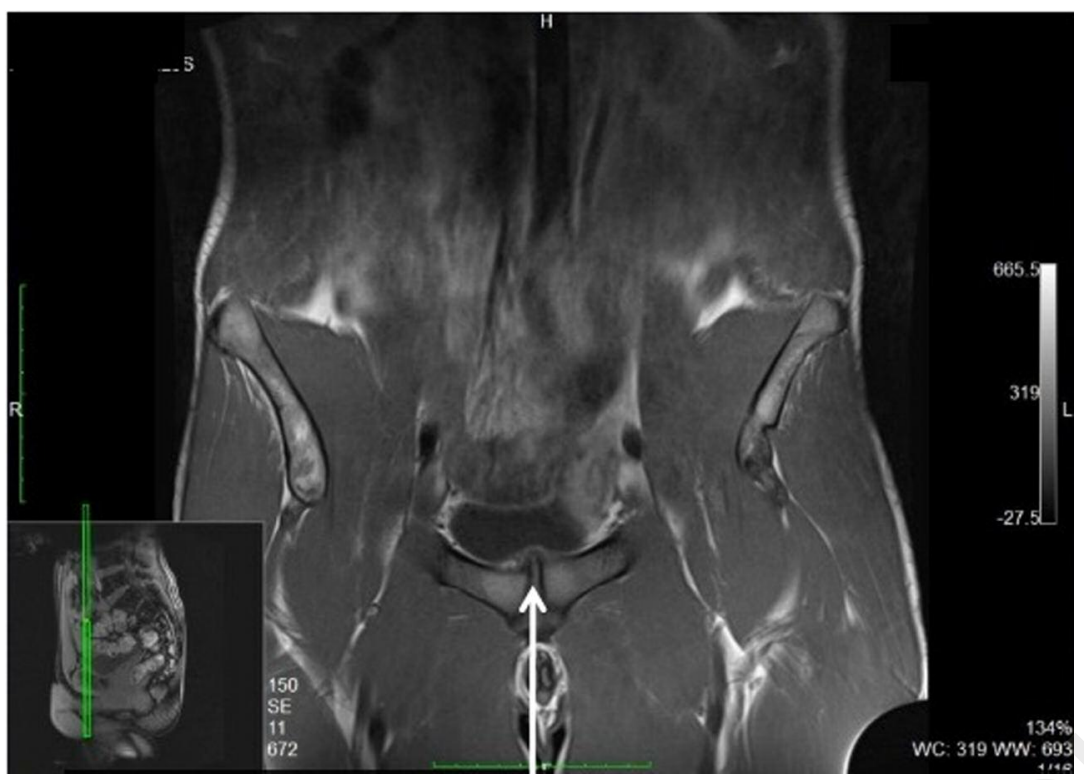

Figure 2. Coronal T1 showing a CDP.

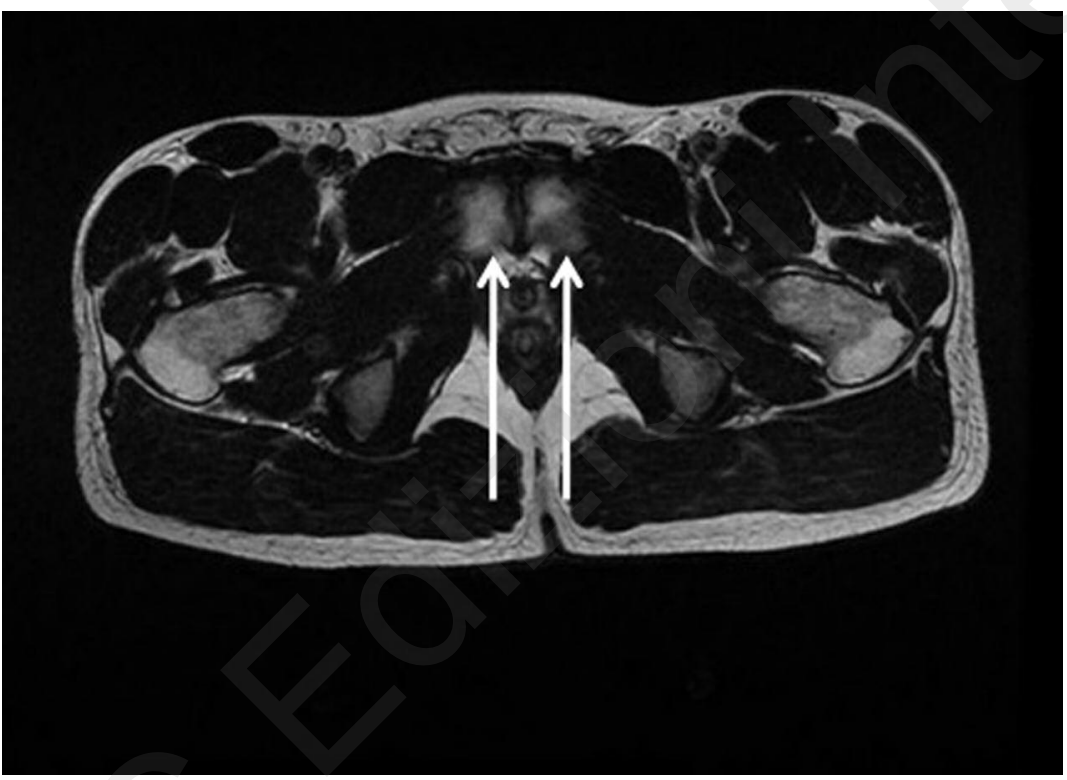

Figure 3. Axial oblique T2 MRI showing a BMO extended across the surface, in the antero-posterior direction. Of both the pubic branches. Depending on its extension, the $\mathrm{BMO}$ is classified as grade 3 .

Our data confirm the presence of BMO supporting an osteitis framework and hence a situation of mechanical overloading at symphysis level. The presence of $\mathrm{BMO}$ is strongly associated (OR $3.68 ; 0.74$ to 18.23 ; $95 \% \mathrm{Cl}$ ) with the presence of $\mathrm{IH}$ and ICPWW. Furthermore, it is interesting to note that the BMO average grade in case of ICPWW was $1.28 \pm 0.45$, while in case of $\mathrm{IH}(\mathrm{F} 1, \mathrm{M} 1-\mathrm{M} 2, \mathrm{~L} 1-\mathrm{L} 2)$ was $2.77 \pm 0.44$ $(p<0.05)$. These data suggest that the BMO severity could be related to the inguinal pathology severity. However, it is important to remember, that the presence of BME may also reflect a simple physiological adaptation to the mechanical stress at symphysis level 26,27 .

\section{SS (Symphysis sclerosis)}

Our findings showed that $50 \%$ of the subjects in SG (versus $12.5 \%$ in $\mathrm{CG}$ ) present $\mathrm{MRI}$ findings of SS $(p<0.001)$. The MRI findings of SS (Fig. 4) is best observed in T1-weighed images. The joint bone portion appears thickened and the sclerotic area appears to be as a bone hypointense formation which extends along the joint margins of the symphysis $3,30,31$. The presence of SS MRI findings in $60 \%$ of the subjects in the $S G$ is in line with previous researches showing an important proportion (between 20 and $98 \%$ ) of SS in athletes suffering from GPS19,21,24,26,40,46-48. Moreover, Kunduracioglu et al. ${ }^{40}$ showed a relationship between SS severity degree and the chronicity of GPS in football players' population, suggesting that the 


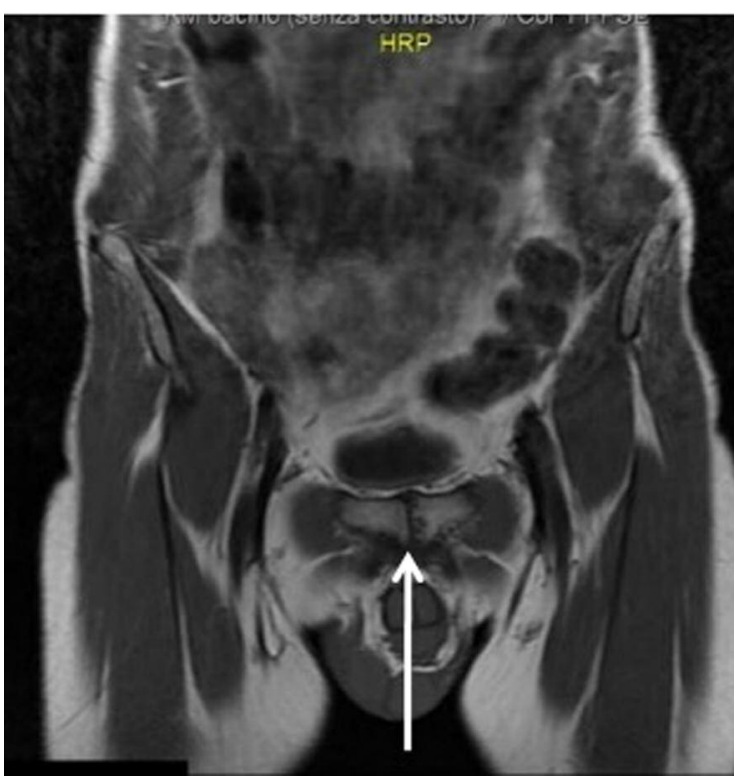

Figure 4. Coronal T1 in which is observable SS.

does not reach a significant statistical level.

SC-JI (Subchondral cyst/joint surface irregularities) We have found that MRI findings of SC-JI was present in $19.17 \%$ of the SG subjects versus $10 \%$ in CG subjects, but the difference was not statistically significant. The joint surface of pubic symphysis should normally be smooth and regular. SC (Fig. 5) is characterized by the presence of an oval formation at sub-chondral level with hyper-intense signal in T2 weighted images. The $\mathrm{Jl}$ are joint surface irregularities observable in T1 and PD images. SC-IJ is a typical sign of severe osteitis pubis ${ }^{49-51}$. Indeed, severe grade osteitis pubis includes enlargement of the symphysis, signs of bone reabsorption and sclerosis of pubic branches cystic and/or osteophyte formations, and in some misdiagnosed cases can progress to bone erosion ${ }^{21}$. Our data confirm that CS-JI, as already showed by other Authors ${ }^{28,31}$, may be present in asymptomatic athletic subject in a percentage ranging from 2724 to $50 \% 47$.

\section{SICS (Secondary inferior cleft sign)}

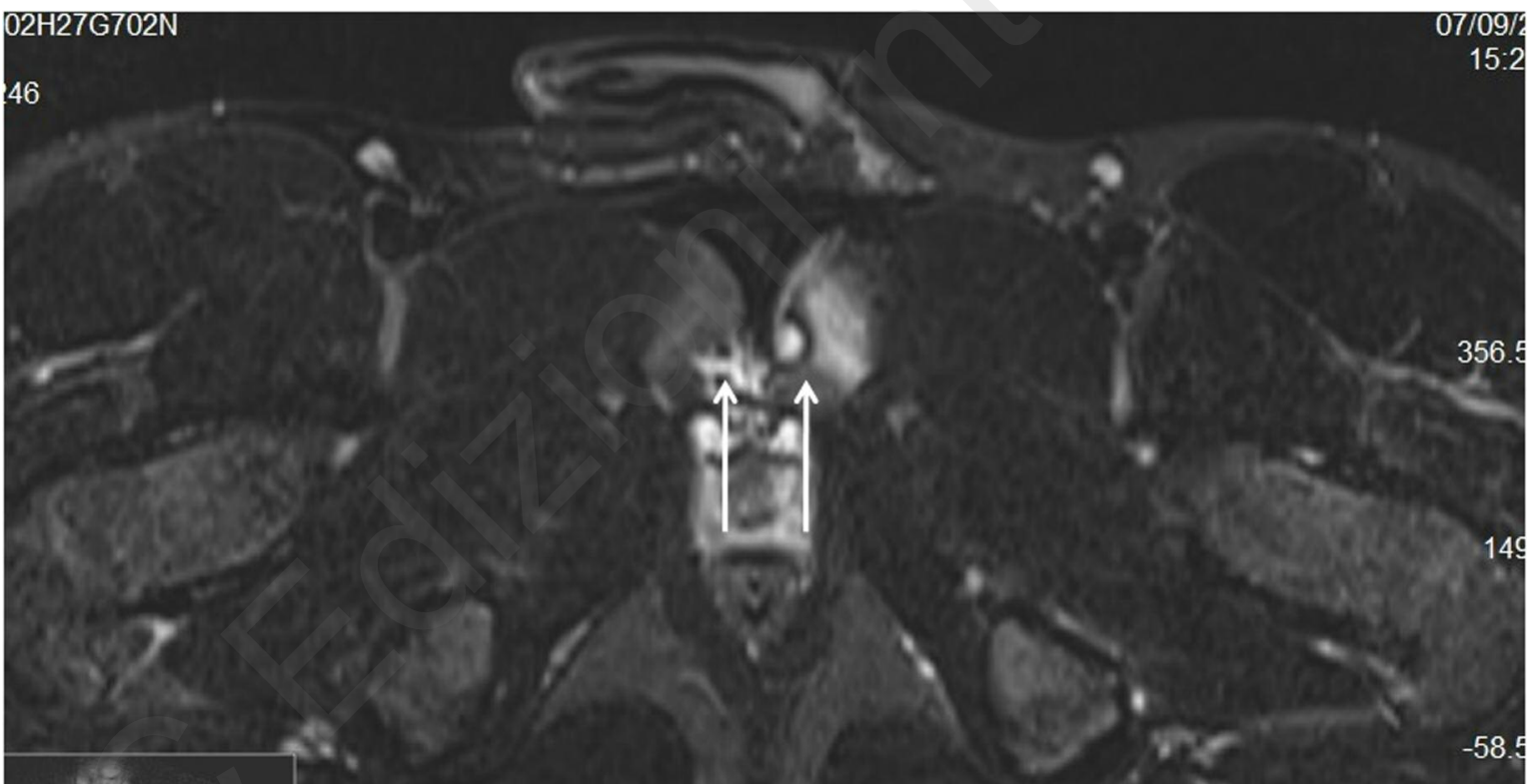

Figure 5. Coronal STIR showing SC-JI.

severity of SS is in correlation to the duration of the GPS symptoms. However, it is important to underline the fact that signs of SS as well as cysts and osteophytes formation at symphysis level may be present also in asymptomatic athletes ${ }^{31}$ depending on the sport activity and increasing in athletes practicing sports like football, tennis, hockey implying increase of the shear forces at symphysis level ${ }^{19,49-51}$. For that reason, MRI findings of SS do not necessarily represent a lesion but can be considered more as an indirect sign of overuse at symphysis level. However, the results of this study show that the value of OD between SS and the presence of $\mathrm{IH}$ and ICPWW
SSCS was present in $10.83 \%$ of SG subjects and was absent in the CG ones, however the difference was not statistically significant. The SICS (Fig. 6) is a hyper-intensity signal line in the fluid-sensitive sequences extending laterally and inferiorly to the lower part of the symphysis. The SICS shows a connection with the symphysis joint space. The SICS must be observable throughout the totality of the joint space and just outside of the symphysis ${ }^{24,48}$. The anatomical dislocation of SICS is inferior to the symphysis, and lower and posterior to the AL insertion ${ }^{24,48}$. SICS is considered a radiological sign of $A L$, fibrocartilaginous pre-symphysis complex and AL - rectus abdomi- 


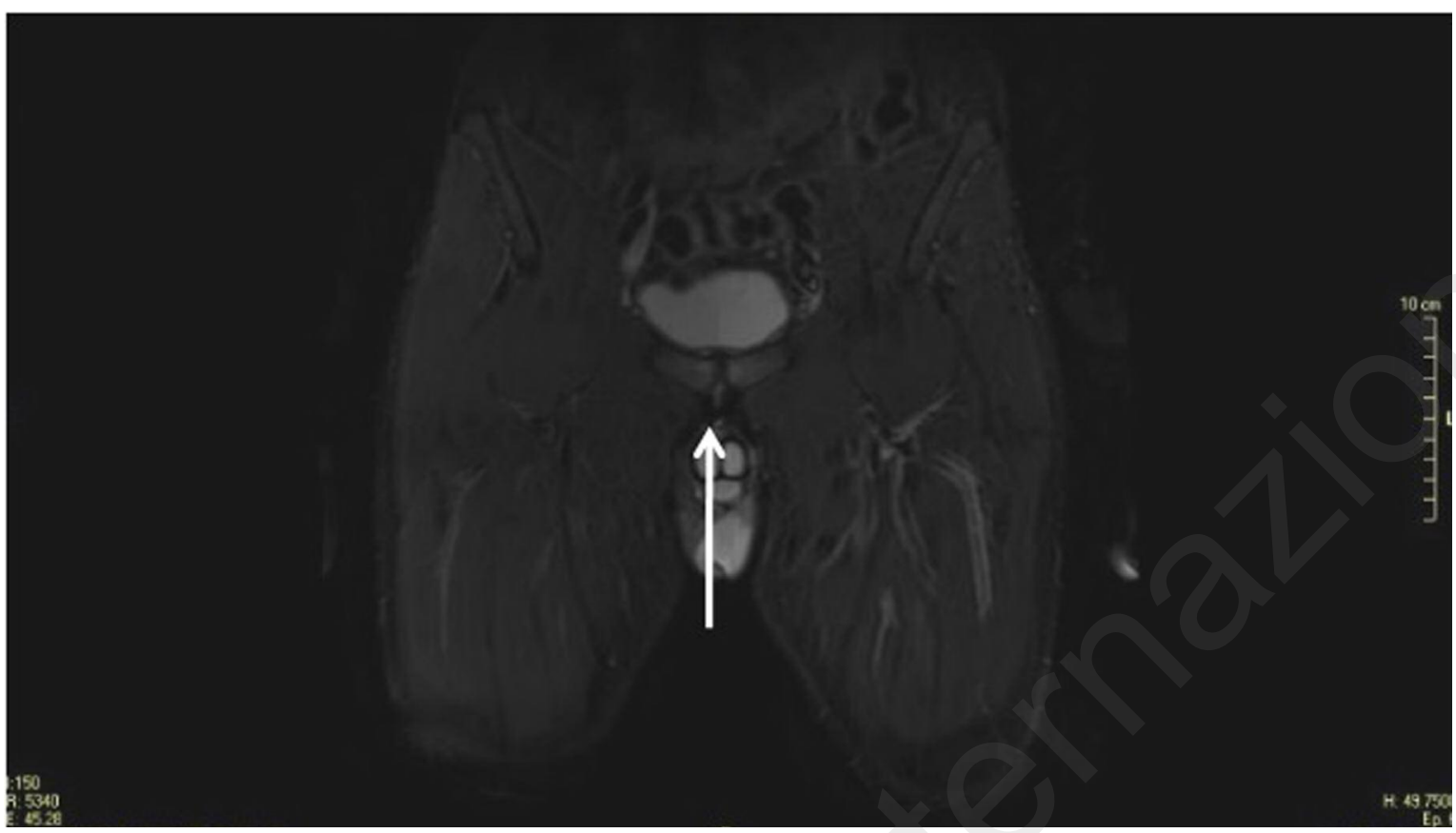

Figure 6. Coronal STIR in which is observable a SICS.

nis common enthesis lesions $24,25,48,52$.

\section{FI (Fatty infiltration in bone marrow at symphysis} joint level)

In our study $\mathrm{FI}$ was present in $5 \%$ of the SG subjects and was absent in the CG ones, with no statistical significant difference. FI (Fig. 7) is the presence of some areas at high-signal intensity at symphysis level in T1 weighted images, while the same areas appear as low density signal in the Fat Sat sequences $18,25,30,31$. FI is present only when both signal changes are present in T1 and Fat Sat sequences (if the change of the signal is present only in the Fat Sat sequences it is insufficient to determine the presence of $\mathrm{FI}$ ). Furthermore, the area/s of altered signal must be very near to the symphysis joint ${ }^{18,25,30,31}$. When the area/s of altered signal observable in $\mathrm{T} 1$ weighted sequences are at bone marrow level, but far from the ar-

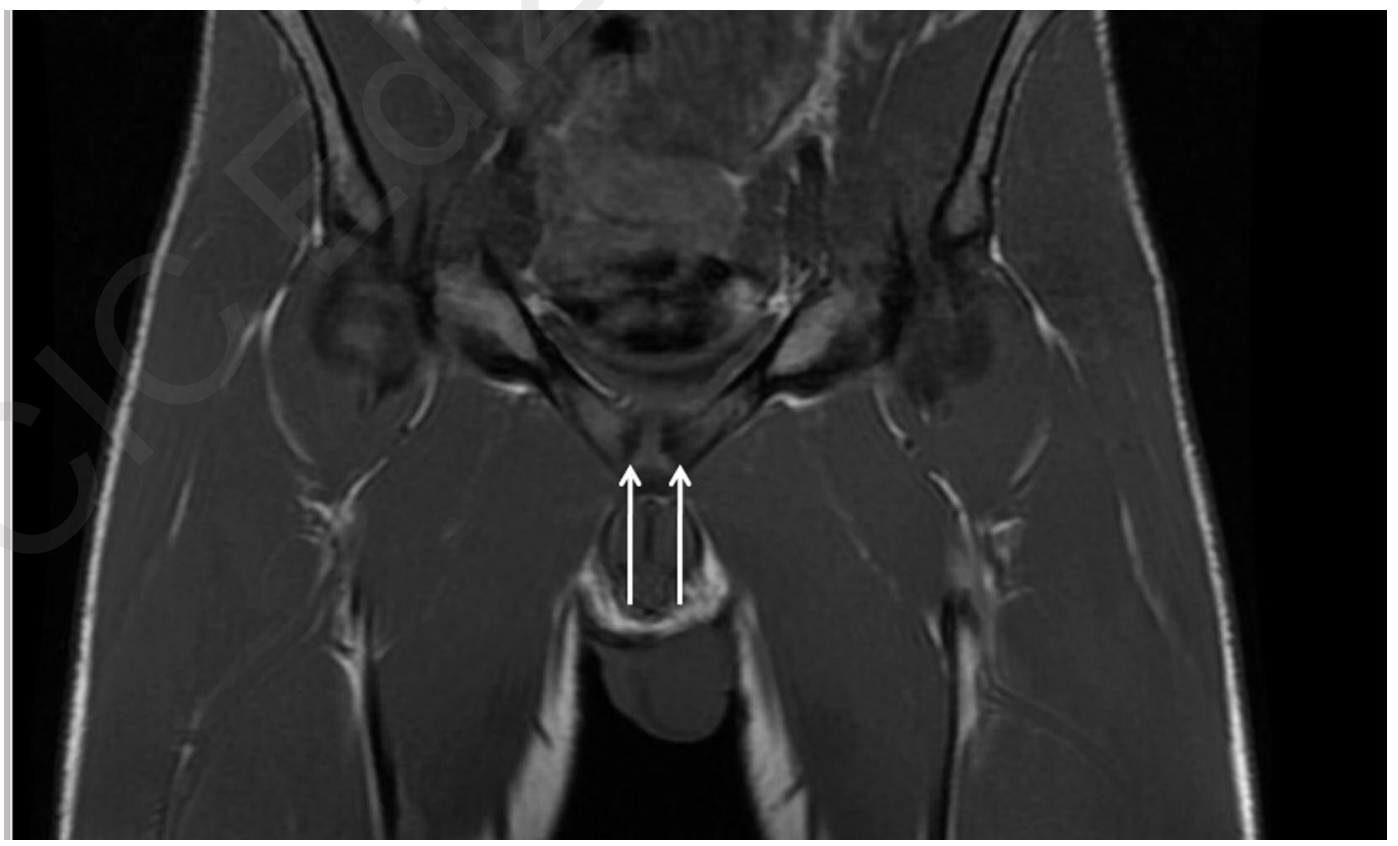

Figure 7. Coronal T1 showing FI. 


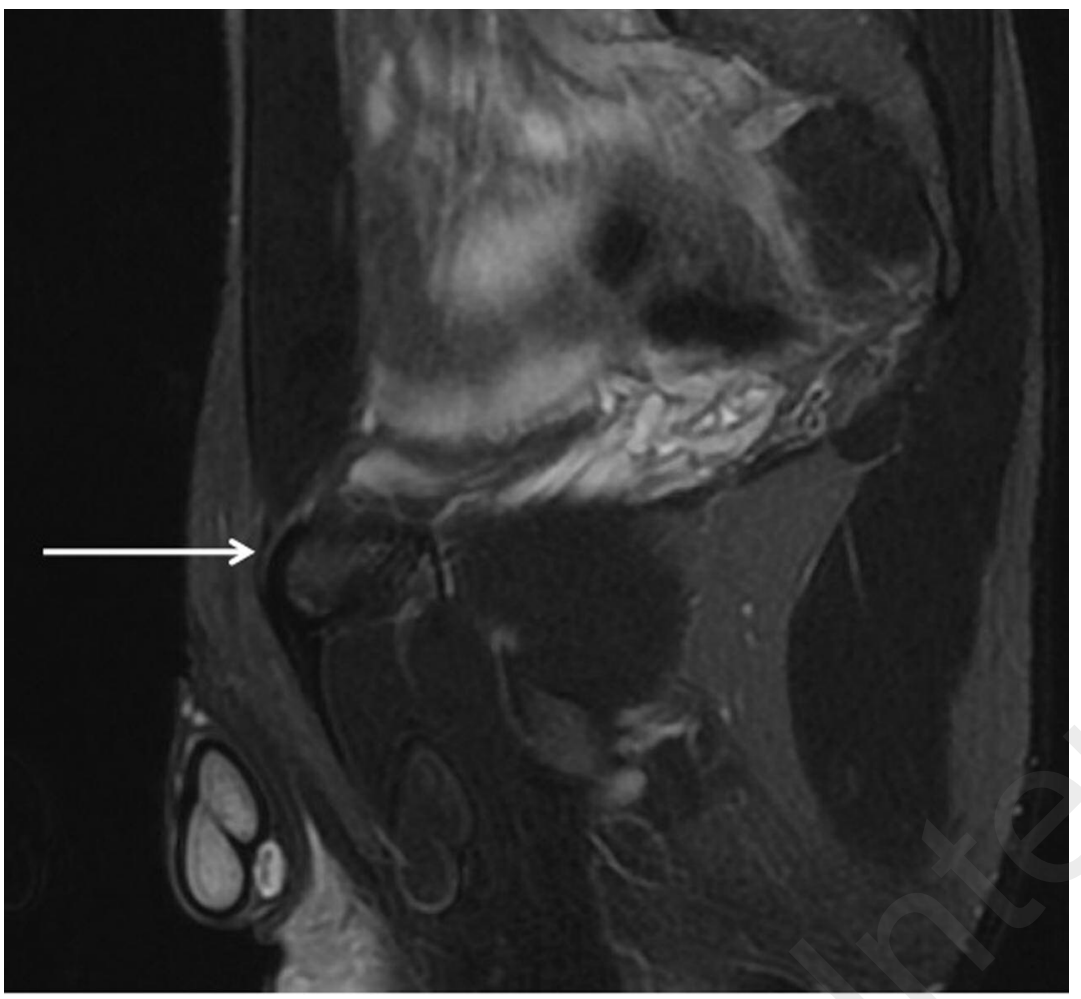

Figure 8. Sagittal STIR showing signs of RAT.

ticular edge of the symphysis, they have to be considered as simple adipose tissue area and not a FI. In other words, FI must directly involve the symphysis 30,31 . The presence of $\mathrm{FI}$ is considered by some Authors like a Modic type II, and therefore it is the sign of a high grade degenerative symphysis framework ${ }^{31}$

\section{RAT (Rectus abdominis tendinopathy)}

RAT was present in $6 \%$ of the SG subjects and was absent in the CG ones with no statistical significant difference. RAT (Fig. 8) is an increased signal intensity in the fluid-sensitive sequence at rectus abdominis muscle-tendon junction level, and/or an increased rectus abdominis tendon volume and is rarely described in literature ${ }^{53,54}$. This may be partially explained by the fact that $A L$ and RA have a common insertion at the pubic symphysis level, and so several RAT could be incorrectly classified as ALT.

\section{SSCS (Secondary superior cleft sign)}

In our study SSCS was present in $3.33 \%$ of the SG subjects and was absent in the CG ones, with no statistically significant difference. SSCS (Fig. 9) is a hyper-intensity signal line in the fluid-sensitive sequences. SSCS is parallel to the lower edge of the upper pubic branch and, like the SISC, shows a connection with the symphysis joint space. When SSCS is present in the coronal STIR images, it is necessary to verify its presence in the axial oblique Fat Sat images. The SSCS is rarely described in the literature ${ }^{30,52}$. For some Authors SSCS is a sign of damage at the pre-symphysis fibrocartilage complex and/or at the rectus abdominis-adductor longus common enthesis $24,48,52$.

\section{PHIL (Parasymphyseal high-intensity line)}

PHIL was present in $5 \%$ of the SG subjects and was absent in the CG ones with no statistically significant difference. PHIL (Fig. 10) is a hyperintensity signal line in the fluid-sensitive sequences within the pubic bone. PHIL is below and parallel to the contour of the joint surface of the symphysis ${ }^{30,31}$. In a PHIL radiological framework, in contrast to SSCS and SICS, there is no communication between PHIL and the joint space. The clinical significance of PHIL is unclear ${ }^{30,31 .}$

\section{Limitations}

A limitation of this study was that all of the patients belonging by CG were amateur athletes, while the SG subjects consisted in a high percentage of professional athletes. Furthermore, there was heterogeneity of the type of sport activities practiced by the subjects included in the study. For these reasons, an interesting development of this study would be to compare the actual recorded data with those that could be obtained by comparing two groups of professional athletes practicing the same sports activity. Other limitation could be considered the limited size of $C G$ and the different timing of MRI assessment.

\section{Conclusions}




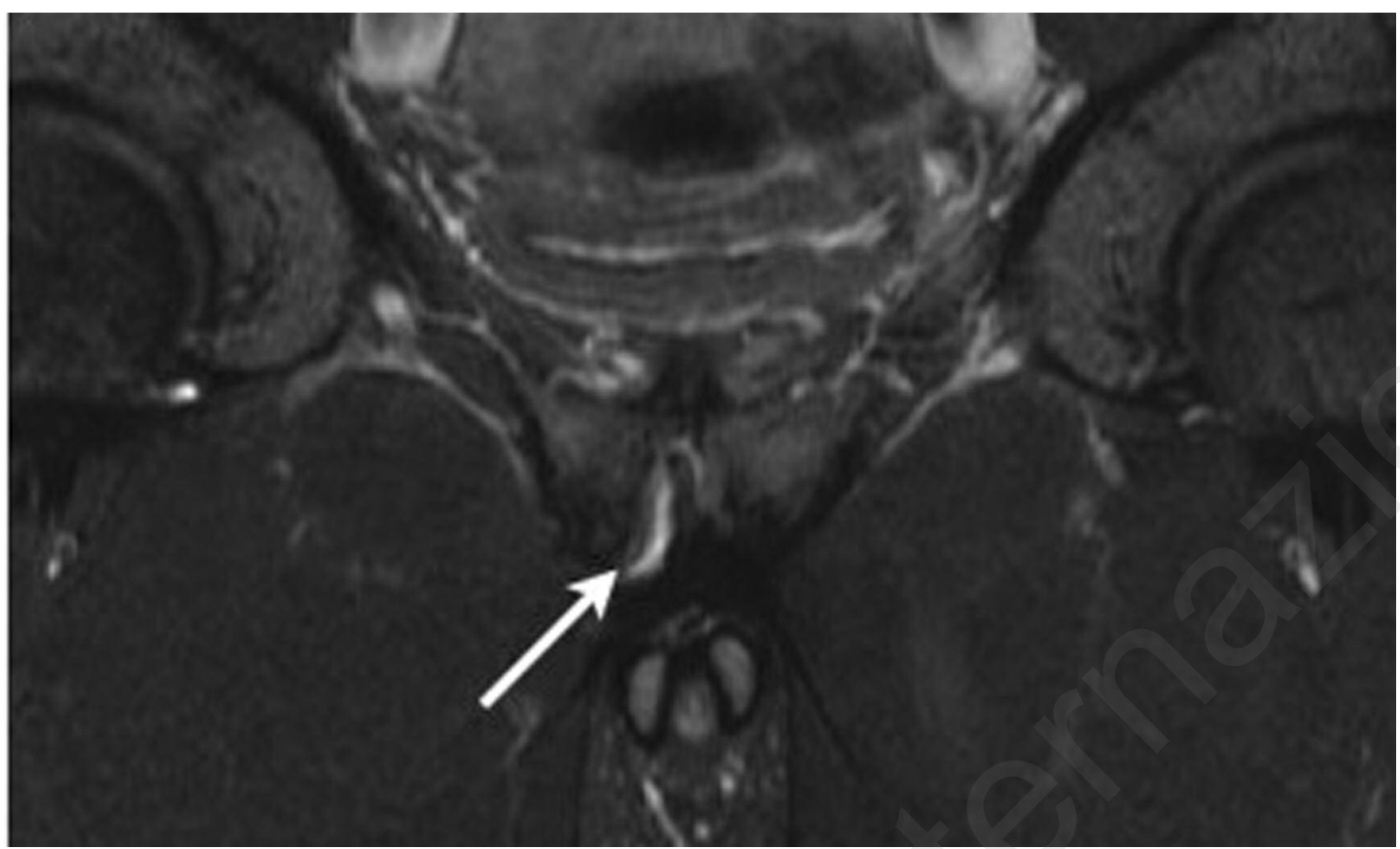

Figure 9. Coronal STIR showing secondary superior cleft sign.

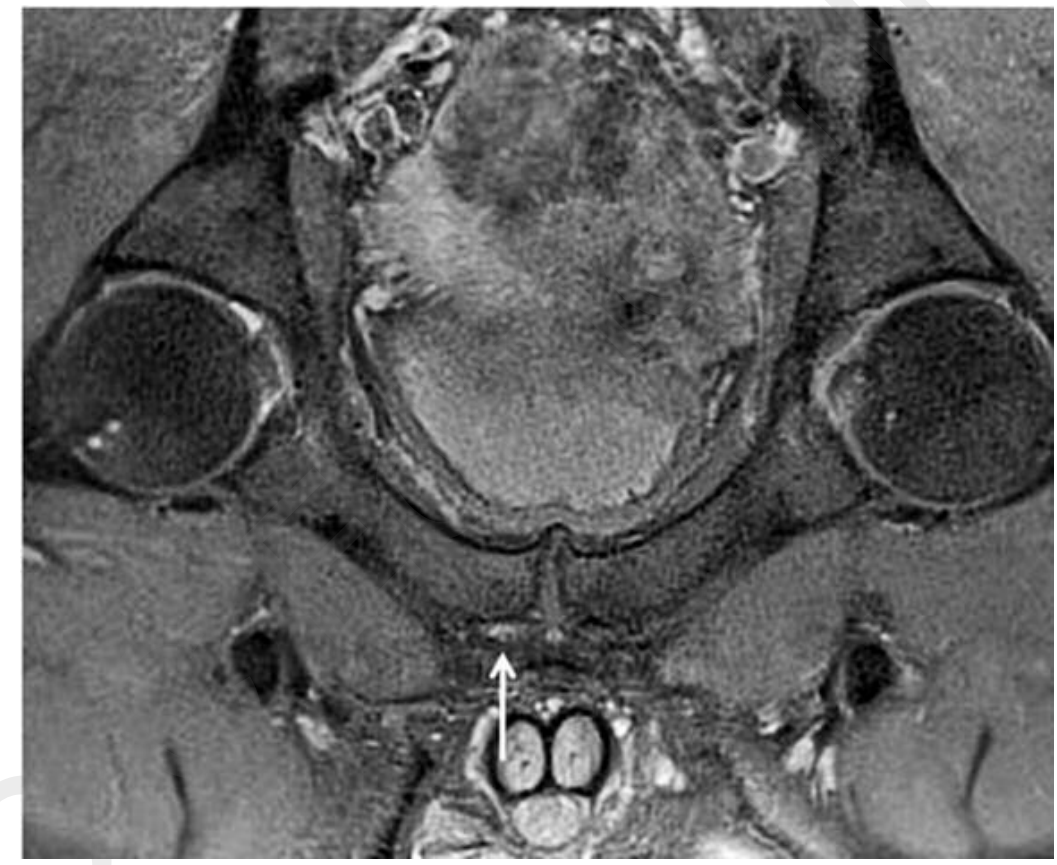

Figure 10. Coronal PD Fat Sat showing parasymphyseal high-intensity line.

$\mathrm{IH}$ and ICPWW represent a frequent clinical framework in LSGPS $4,19,20,55$. In case of suspected presence of $\mathrm{IH}$ and ICPWW the gold standard imaging is represented by dynamic US ${ }^{14}$ which shows a very high PPV 14-17. This study has confirmed the multifactorial aetiology of GPS, and the overlapping of several clinical frameworks which is a common characteris- tic of LSGPS $3,4,19$. For this reason a standard MRI protocol can provide some important information concerning potential clinical entities correlated with the presence of $\mathrm{IH}$ and ICPWW. Therefore, in the view of these results the presence of ALT, CDP and BMO at $\mathrm{MRI}$ assessment can make suspect the presence of $\mathrm{IH}$ and ICPWW and obviously vice versa. Furthermore, the results of this study show how in particular 
clinical frameworks of GPS (i.e LSGPS) it is necessary both MRI and dynamic US assessment.

\section{References}

1. Sheen AJ, Stephenson BM, Lloyd DM, Robinson P, Fevre D, Paajanen H, de Beaux A, Kingsnorth A, Gilmore OJ, Bennett D, Maclennan I, O'Dwyer P, Sanders D, Kurzer M. "'Treatment of the sportsman's groin": British Hernia Society's 2014 position statement based on the Manchester Consensus Conference. Br J Sports Med. 2014 Jul;48(14):1079-1087.

2. Weir A, Brukner P, Delahunt E, Ekstrand J, Griffin D, Khan KM, Lovell G, Meyers WC, Muschaweck U, Orchard J, Paajanen H, Philippon M, Reboul G, Robinson P, Schache AG, Schilders E, Serner A, Silvers H, Thorborg K, Tyler T, Verrall G, de Vos RJ, Vuckovic Z, Hölmich P. Doha agreement meeting on terminology and definitions in groin pain in athletes. $\mathrm{Br} \mathrm{J}$ Sports Med. 2015 Jun;49(12):768-774.

3. Bisciotti GN, Volpi P, Zini R, et al. Groin Pain Syndrome Italian Consensus Conference on terminology, clinical evaluation and imaging assessment in groin pain in athlete. BMJ Open Sport Exerc Med. 2016;2:e000142. Doi:10.1136/ bmjsem2016-000142.

4. Bisciotti GN, Di Marzo F, Auci A, Parra F, Cassaghi G, Corsini A, Petrera M, Volpi P, Vuckovic Z, Panascì M, Zini R. Cam morphology and inguinal pathologies: is there a possible connection? Journal of Orthopaedics and Traumatology. 2017 Sep 18. Doi: 10.1007/s10195-017-0470-y. [Epub ahead of print].

5. Gilmore J. Groin pain in the soccer athlete: fact, fiction, and treatment. Clin Sports Med. 1998 Oct;17(4):787-793.

6. Sayad P, Abdo Z, Cacchione R, Ferzli G. Incidence of incipient contralateral hernia during laparoscopic hernia repair. Surg Endosc. 2000 Jun;14(6):543-545.

7. Irshad K, Feldman LS, Lavoie C, Lacroix VJ, Mulder DS, Brown RA. Operative management of "hockey groin syndrome": 12 years of experience in National Hockey League players. Surgery. 2001 Oct;130(4):759-764; discussion 764-6.

8. Garvey JF, Hazard H. Sports hernia or groin disruption injury? Chronic athletic groin pain: a retrospective study of $100 \mathrm{pa}-$ tients with long-term follow-up. Hernia. 2014;18(6):815-823.

9. Paksoy M, Sekmen Ü. Sportsman hernia; the review of current diagnosis and treatment modalities. Ulus Cerrahi Derg. 2015 Aug 18;32(2):122-129.

10. Pokorny H, Resinger C, Fischer I, Lorenz V, Noske H, Podar S, Längle F, Schrittwieser R. Fast Early Recovery After Transabdominal Preperitoneal Repair in Athletes with Sportsman'sGroin: A Prospective Clinical Cohort Study. J Laparoendosc Adv Surg Tech A. 2017 Mar;27(3):272-276.

11. Zoland MP, Maeder ME, Iraci JC, Klein DA. Referral Patterns for Chronic Groin Pain and Athletic Pubalgia/Sports Hernia: Magnetic Resonance Imaging Findings, Treatment, and Outcomes. Am J Orthop (Belle Mead NJ). 2017 Jul/Aug;46(4): E251-E25.

12. Larson CM. Sports hernia/athletic pubalgia: evaluation and management. Sports Health. 2014 Mar;6(2):139-144.

13. Towfigh S. Obscure groin pain in women. In: Inguinal hernia surgery. G Campanelli (Ed). Springer-Verlag Italia. 2017.

14. Alabraba E, Psarelli E, Meakin K, Quinn M, Leung M, Hartley $\mathrm{M}$, Howes $\mathrm{N}$. The role of ultrasound in the management of patients with occult groin hernias. Int J Surg. 2014;12(9):918922.

15. Van den Berg JC, de Valos JC, Go PM, Rosenbusch G. Detection of groin hernia with physical examination, ultrasound, and MRI compared with laparoscopic findings. Invest Radiol. 1999 Dec;34(12):739-743.

16. Bradley M, Morgan D, Pentlow B, Roe A. The groin hernia - an ultrasound diagnosis? Ann R Coll Surg Engl. 2003 May;85 (3):178-180.

17. Bradley M, Morgan J, Pentlow B, Roe A. The positive predictive value of diagnostic ultrasound for occult herniae. Ann R Coll Surg Engl. 2006 Mar;88(2):165-167.

18. Omar IM, Zoga AC, Kavanagh EC, Koulouris G, Bergin D, Gopez AG, Morrison WB, Meyers WC. Athletic pubalgia and "sports hernia": optimal MR imaging technique and findings. Radiographics. 2008 Sep-Oct;28(5):1415-1438.

19. Bisciotti GN, Auci A, Di Marzo F, Galli R, Pulici L, Carimati G Quaglia A, Volpi P. Groin pain syndrome: an association of different pathologies and a case presentation. Muscles Ligaments Tendons J. 2015 Oct 20;5(3):214-222.

20. Taylor R, Vuckovic Z, Mosler A, Agricola R, Otten R, Jacobsen P, Holmich P, Weir A. Multidisciplinary Assessment of 100 Athletes With Groin Pain Using the Doha Agreement: High Prevalence of Adductor-Related Groin Pain in Conjunction With Multiple Causes. Clin J Sport Med. 2017 Jun 22. [Epub ahead of print].

21. Albers SL, Spritzer CE, Garrett WE Jr, et al. MR findings in athletes with pubalgia. Skeletal Radiol. 2001;30:270-277.

22. Robinson P, Hensor E, Lansdown MJ, Ambrose NS, Chapman $\mathrm{AH}$. Inguinofemoral hernia: accuracy of sonography in patients with indeterminate clinical features. Am J Roentgenol. 2006;187(5):1168-1178.

23. Slavotinek JP, Verrall GM, Fon GT, Sage MR. Groin pain in footballers: the association between preseason clinical and pubic bone magnetic resonance imaging findings and athlete outcome. Am J Sports Med. 2005 Jun;33(6):894-899.

24. Cunningham PM, Brennan D, O'Connell M, et al. Patterns of bone and soft-tissue injury at the symphysis pubis in soccer players: observations at MRI. AJR Am J Roentgenol. 2007;188:W291-296.

25. Zoga AC, Kavanagh EC, Omar IM, et al. Athletic pubalgia and the "sports hernia": MR imaging findings. Radiology. 2008:247:797-807.

26. Paajanen $\mathrm{H}$, Hermunen $\mathrm{H}$, Karonen J. Pubic magnetic resonance imaging findings in surgically and conservatively treated athletes with osteitis pubis compared to asymptomatic athletes during heavy training. Am J Sports Med. 2008;36:117121.

27. Paajanen $\mathrm{H}$, Hermunen $\mathrm{H}$, Karonen J. Effect of heavy training in contact sports on MRI findings in the pubic region of asymptomatic competitive athletes compared with non-athlete controls. Skeletal Radiol. 2011 Jan;40(1):89-94.

28. Branci S, Thorborg K, Nielsen MB, Hölmich P. Radiologica findings in symphyseal and adductor-related groin pain in athletes: a critical review of the literature. Br J Sports Med. 2013 Jul;47(10):611-619.

29. Zoga C. Imaging athletic pubalgia and core muscle injury. Relevance for sports medicine. ASPETAR Sport Med J. 2014;1: 58-65.

30. Branci S, Thorborg K, Bech BH, Boesen M, Magnussen E, Court-Payen M, Nielsen MB, Hölmich P. The Copenhagen Standardised MRI protocol to assess the pubic symphysis and adductor regions of athletes: outline and intratester and intertester reliability. Br J Sports Med. 2015 May;49(10):692699.

31. Branci S, Thorborg K, Bech BH, Boesen M, Nielsen MB, Hölmich P. MRI findings in soccer players with long-standing adductor-related groin pain and asymptomatic controls. $\mathrm{Br} \mathrm{J}$ Sports Med. 2015 May;49(10):681-691.

32. Von Elm E, Altman DG, Egger M, et al. The strengthening reporting of observational studies in epidemiology (STROBE) statement: guidelines for observational studies. Lancet. 2007;370:1453-1457.

33. Hoffmann TC, Glasziou PP, Boutron I, et al. Better reporting of interventions: template for intervention description and replica- 
tion (TIDieR) checklist and guide. BMJ. 2014;348:g1687.

34. Delahunt E, Thorborg K, Khan KM, et al. Minimum reporting standards for clinical research on groin pain in athletes. $\mathrm{Br} \mathrm{J}$ Sports Med. 2015;49:775-781.

35. Padulo J, Oliva F, Frizziero A, Maffulli N. Muscles, Ligaments and Tendons Journal - Basic principles and recommendations in clinical and field science research: 2016 update. MLTJ. 2016;6(1):1-5.

36. Miserez M, Alexandre JH, Campanelli G, Corcione F, Cuccurullo D, Pascual $\mathrm{MH}$, Hoeferlin A, Kingsnorth AN, Mandala V, Palot JP, Schumpelick V,Simmermacher RK, Stoppa R, Flament JB. The European hernia society groin hernia classification: simple and easy to remember. Hernia. $2007 \mathrm{Apr} ; 11(2)$ : 113-116.

37. Hammoud S, Bedi A, Magennis E, Meyers WC, Kelly BT. High incidence of athletic pubalgia symptoms in professional athletes with symptomatic femoroacetabular impingement. Arthroscopy. 2012;28(10):1388-1395.

38. Hammoud S, Bedi A, Voos JE, Mauro CS, Kelly BT. The recognition and evaluation of patterns of compensatory injury in patients with mechanical hip pain. Sports Health. 2014;6 (2):108-118.

39. Rambani R, Hackney R. Loss of range of motion of the hip joint: a hypothesis for ethiology of sports hernia. Muscles Ligaments Tendons J. 2015 Mar 27;5(1):29-32.

40. Kunduracioglu B, Yilmaz C, Yorubulut M, et al. Magnetic resonance findings of osteitis pubis. J Magn Reson Imaging. 2007;25:535-539.

41. Gibbon WW, Schilders E. Pelvis, hip and groin. In: Vanhoenacker FM, Maas M, Gielen JL, eds. Imaging of orthopedic sports injuries. 1st edn. Berlin, New York: Springer. 2007:235263.

42. Yao L, Pitts JT, Thomasson D. Isotropic 3D fast spin-echo with proton-density-like contrast: a comprehensive approach to musculoskeletal MRI. AJR Am J Roentgenol. 2007;188:199201.

43. Modic MT, Steinberg PM, Ross JS, et al. Degenerative disk disease: assessment of changes in vertebral body marrow with MR imaging. Radiology. 1988;166:193-199.

44. Verrall GM, Slavotinek JP, Fon GT, Barnes PG. Outcome of conservative management of athletic chronic groin injury diagnosed as pubic bone stress injury. Am J Sports Med. 2007;35 (3):467-474.

45. Verrall GM, Henry L, Fazzalari NL, Slavotinek JP, Oakeshott $\mathrm{RD}$. Bone biopsy of the parasymphyseal pubic bone region in athletes with chronic groin injury demonstrates new woven bone formation consistent with a diagnosis of pubic bone stress injury. Am J Sports Med. 2008;36(12):2425-2431.

46. Rubin AD. Imaging in athletic groin pain. In: Sports hernia and athletic pubalgia. Diduch DR, Brunt LM (Editors). Springer (Ed). New York. 2014.

47. Verrall GM, Slavotinek JP, Fon GT. Incidence of pubic bone marrow oedema in Australian rules football players: relation to groin pain. Br J Sports Med. 2001;35:28-33.

48. Brennan D, O'Connell MJ, Ryan M, Cunningham P, Taylor D, Cronin C, O'Neill P, Eustace S. Secondary cleft sign as a marker of injury in athletes with groin pain: MR image appearance and interpretation. Radiology. 2005 Apr;235(1):162-167.

49. Farber AJ, Wilckens JH. Sports hernia: diagnosis and therapeutic approach. J Am Acad Orthop Surg. 2007;15:507-514.

50. Feeley BT, Powell JW, Muller MS, Barnes RP, Warren RF, Kelly BT. Hip injuries and labral tears in the National Football League. Am J Sports Med. 2008;36:2187-2195.

51. Volpi P, Bisciotti GN. Impingement femoro-acetabolare e ernia da sport: associazione, eziopatogenesi e prevenzione. Minerva Ortopedica e Traumatologica. 2015 Ott;66(5):223-229.

52. Murphy G, Foran P, Murphy D, Tobin O, Moynagh M, Eustace $\mathrm{S}$. "Superior cleft sign" as a marker of rectus abdominus/adductor longus tear in patients with suspected sportsman's hernia. Skeletal Radiol. 2013 Jun;42(6):819-825.

53. Hölmich P. Long-standing groin pain in sportspeople falls into three primary patterns, a "clinical entity" approach: a prospective study of 207 patients. Br J Sports Med. 2007;41:247-252.

54. Werner J, Hagglund M, Walden M, et al. UEFA injury study: a prospective study of hip and groin injuries in professional football over seven consecutive seasons. Br J Sports Med. 2009:43:1036-1040.

55. Lovell G. The diagnosis of chronic groin pain in athletes: a review of 189 cases. Aust J Sci Med Sport. 1995;27:76-79. 